\title{
Padrões de distribuição geográfica de Passiflora L. subg. Decaloba (DC.) Rchb. (Passifloraceae s.s.)
}

\section{Natália Brandão Gonçalves Fernandes ${ }^{1,2, *}$ e Michaele Alvim Milward-de-Azevedo ${ }^{1,2}$}

\author{
${ }^{1}$ Universidade do Estado do Rio de Janeiro. Programa de Pós-Graduação em \\ Biologia Vegetal. Rua São Francisco Xavier, 524. Maracanã. Rio de Janeiro-RJ, Brasil \\ (CEP 20550-013).*E-mail: brandaonatalia@outlook.com. \\ ${ }^{2}$ Universidade Federal Rural do Rio de Janeiro. Campus Três Rios. Departamento \\ de Ciências do Meio Ambiente. Laboratório de Diversidade Vegetal. Avenida \\ Prefeito Alberto da Silva Lavinas, 1847. Centro. Três Rios-RJ, Brasil \\ (CEP 25802-100).
}

Resumo. A distribuição geográfica de espécies vegetais, tem sido foco de vários estudos ao longo do tempo, principalmente para determinação de padrões de distribuição que caracterizem a área de preferência das espécies. A Família Passifloraceae sensu stricto possui desde espécies de ampla distribuição, até táxons muito restritos. 0 subgênero Decaloba, pertencente ao gênero Passiflora, possui distribuição tropical e subtropical e abrange cerca de 235 espécies, divididas em oito superseções. Foram levantados os dados de ocorrência das espécies do subgênero Decaloba nos sítios eletrônicos dos herbários virtuais. A plotagem dos mapas foi realizada com auxílio do SimpleMappr. A maior parte das espécies ocorre na América Central e do Sul, enquanto uma pequena parte dividiu-se entre a Ásia e Oceania, em diferentes padrões biogeográficos.

Palavras-chave: Biogeografia; Neotrópico; Centro de dispersão.

Abstract. Patterns of geographic distribution of Passiflora $L$. subg. Decaloba (DC.) Rchb. (Passifloraceae s.s.). Geographic distribution of plant species has been the focus of several studies over time, mainly to determine distribution patterns that characterize the species' preferred area. The Family Passifloraceae sensu stricto ranges from widely distributed species to very restricted taxa. The subgenus Decaloba, belonging to the genus Passiflora, has a tropical and subtropical distribution and covers about 235 species, divided into eight supersections. Data on the occurrence of species of the subgenus Decaloba were collected on the websites of virtual herbariums. The plotting of the maps was carried out with the aid of SimpleMappr. Most species occur in Central and South America, while a small part was divided between Asia and Oceania, in different biogeographic patterns.
Recebido

03/06/2021

Aceito

26/07/2021

Disponível on line 31/07/2021

Publicado 31/08/2021

Acesso aberto

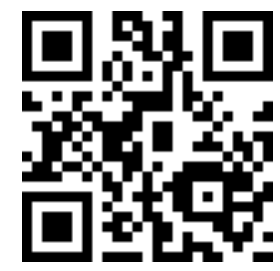

ORCi

(1) 0000-0003-3348-2619

Natália Brandão

Gonçalves Fernandes

(1) 0000-0001-8076-5561

Michaele Alvim

Milward-de-Azevedo 
Keywords: Biogeography; Neotropics; Center of dispersion.

\section{Introdução}

As questões sobre processos biogeográficos têm sido abordadas em diversos estudos, principalmente relacionados à distribuição dos organismos (Thorne, 2004; Collevatti et al., 2009). A distribuição geográfica de um determinado táxon foi apontada por Brown e Lomolino (2006) como uma expressão complexa, tanto ecológica, quanto evolutiva, ocasionada por uma gama de fatores relacionados às especificidades de cada espécie, como, por exemplo, o potencial de dispersão.

Há muito tempo é relatado que as espécies não possuem uma distribuição homogênea em relação à superfície terrestre (MacArthur, 1965; Brown, 1988). A riqueza de espécies pode ser definida como maior em regiões tropicais e tende a diminuir em maiores latitudes (Hawkins et al., 2003). É possível compreender os padrões geográficos em níveis taxonômicos diferentes, assim como, entender sua distribuição em escalas globais e continentais, evidenciando os táxons por centros de diversidade análogos ou por sua área de distribuição (Marchioretto, 2009).

As espécies vegetais têm influência em diversas esferas na sociedade, por estarem relacionadas principalmente à saúde e à economia, portanto tem sido um foco de atenção compreender sua distribuição geográfica e quais fatores limitam sua ocorrência. Dentro destes aspectos, as espécies diretamente relacionadas a fins econômicos são as mais detalhadas no que diz respeito à sua distribuição e são as que possuem espécies geograficamente mais amplas e abundantes (Barreto, 2008). Deste modo, as espécies com características mais conservacionistas, com distribuição restrita, incluindo a maior parte das espécies ameaçadas ou raras, não fazem parte do interesse geral da sociedade e são pouco avaliadas geograficamente (Barreto, 2008).

A Família Passifloraceae sensu stricto (s.s.) apresenta um grande interesse econômico, tanto relacionado a fins alimentícios, quanto ao uso medicinal. Milward-de-Azevedo (2008) fez uma análise sistêmica sobre a valoração dos fitoterápicos derivados de Passifloraceae s.s. e abordou o relevante uso das espécies, cada uma com sua particularidade medicinal e a maioria com fins ansiolíticos. Porém, essas espécies também possuem grande importância ecológica, devido à íntima relação que possui com a fauna, por causa da peculiaridade de suas flores e frutos (Varassin, 2001).

Passifloraceae s.s. possui cerca de 17 gêneros e mais de 700 espécies, sua distribuição geográfica engloba as regiões tropicais e subtropicais, abrangendo maior diversidade na Região Neotropical (MacDougal e Feuillet, 2004). 0 gênero Passiflora L. é o maior representante da família e possui seis subgêneros, Astrophea (DC.) Mast., Decaloba (DC.) Rchb., Deidamioides (Harms) Killip, Passiflora (MacDougal e Feuillet, 2004), Tetrapathea (DC.) P. S. Green e Tryphostemmatoides (Harms) Killip.

Passiflora subg. Decaloba é pantropical, com aproximadamente 235 espécies, dividido em oito superseções, Decaloba (DC.) J.M. MacDougal \& Feuillet, que detém o maior número de espécies e compõe quase metade de todo o subgênero, Auriculata J.M. MacDougal \& Feuillet, Bryonioides (Harms) J.M. MacDougal \& Feuillet, Cieca (Medic.) J.M. MacDougal \& Feuillet, Disemma (Labill.) J.M. MacDougal \& Feuillet, Hahniopathantus (Harms) J.M. MacDougal \& Feuillet, Multiflora (Small) J.M. MacDougal \& Feuillet e Pterosperma (L. Gilbert \& J.M. MacDougal) J.M. MacDougal \& Feuillet (MacDougal e Feuillet, 2004).

O subgênero Decaloba ocorre do norte da Argentina até o sul dos Estados Unidos, e, segundo Ulmer e MacDougal (2004), na América Central há uma ampla concentração de táxons desse subgênero, inclusive endêmicos, podendo considerá-lo como seu provável centro de dispersão. Segundo estes autores, do total de espécies do subgênero, 20 são 
nativas do sudeste da Ásia e Austrália. Por apresentar um centro de diversidade que abrange os países do México (59 espécies), Colômbia (56 espécies) e Guatemala (40 espécies), além de exemplares nos Estados Unidos, América Central e do Sul, Ásia, Austrália e no Pacífico, tornou-se o subgênero com a maior distribuição geográfica (Krosnick et al., 2013). No Brasil são reconhecidas 26 espécies (Bernacci et al., 2020).

Este subgênero é representado por trepadeiras herbáceas, com estípulas linearsubuladas ou falcadas, às vezes foliáceas, podem ou não conter ocelos nas lâminas foliares, dispõe flores pequenas $(<4 \mathrm{~cm}$ de diâmetro), apresentam uma ou duas séries de filamentos da corona e opérculo plicado, os frutos podem ser caracterizados como bagas ou cápsulas e as sementes podem ser reticuladas, foveoladas ou transversalmente sulcadas (Milward-de-Azevedo et al., 2012).

0 presente estudo tem como objetivo realizar o levantamento da distribuição geográfica das superseções de Passiflora subg. Decaloba, estabelecendo padrões de distribuição e apontando possíveis rotas migratórias.

\section{Material e métodos}

O levantamento das espécies de Passiflora subg. Decaloba, assim como a obtenção dos dados geográficos de ocorrência, foram realizados através da visualização dos materiais depositados nos herbários virtuais, nos sítios eletrônicos do Species Link (http://splink.cria.org.br/), JABOT (http://aplicacoes.jbrj.gov.br/jabot/v2/consulta.php) e Tropicos ${ }^{\circledR}$ (http://www.tropicos.org/).

O mapeamento da distribuição geográfica de cada superseção foi elaborado com base nas localidades citadas pelos coletores, transformados em pontos, de acordo com as coordenadas geográficas encontradas, utilizando o programa ArcGis para plotar os pontos de coleta e estabelecer as áreas de ocorrência e elaborar os mapas de distribuição geográfica. Em seguida foi utilizado o sítio eletrônico SimpleMappr (http://www.simplemappr.net/) (Shorthouse, 2010), para delimitar os polígonos de padrão de ocorrência das superseções. Os padrões foram divididos em contínuo, quando a ocorrência é ininterrupta, ou disjunto, quando existem duas ou mais regiões de ocorrência, separadas por áreas em que a espécie não vive, mesmo com condições apropriadas.

Foi utilizado o estudo de Chen e Chen (2013) sobre a classificação do clima de Köppen para definir as características climáticas e de vegetação das áreas de ocorrência do subgênero Decaloba.

\section{Resultados}

Foram registradas a distribuição geográfica de 205 espécies de Passiflora subg. Decaloba, quatro pertencentes à superseção Auriculata, 19 à Bryonioides, 16 a Cieca, 117 à Decaloba, 21 à Disemma, cinco à Hahniopathantus, 19 à Multiflora, e bem como quatro à Pterosperma.

As superseções em sua maioria possuem ampla distribuição, sendo apenas a superseção Pterosperma caracterizada como restrita, as espécies dessa superseção ocorrem apenas em países da América Central e possuem pouquíssimos registros. 0 padrão de distribuição ficou dividido entre contínuo e disjunto, onde seis das superseções foram caracterizadas como padrão contínuo e apenas duas como padrão disjunto. 0 país com maior ocorrência do subgênero foi a Costa Rica, que apresentou sete das oito superseções analisadas neste estudo, seguido da Guatemala e do México que possuem pelo menos seis das superseções. 0 México foi o país com maior riqueza registrada para o subgênero totalizando 59 espécies, seguido pela Guatemala e a Costa Rica, com 32 e 29 espécies, respectivamente. 
As espécies que aparecem fora do continente americano, são pertencentes a superseção Disemma, que possui distribuição apenas para o continente asiático e parte da Oceania. A maior riqueza registrada foi na China, com 13 das 21 espécies e a menor riqueza foi no território australiano com três espécies endêmicas do país pertencentes à superseção.

A distribuição da superseção Auriculata (Figura 1-a) foi identificada nas áreas da América Central e região norte, nordeste e oeste da América do Sul. As características climáticas e fisionômicas da área são equatoriais de florestas tropicais úmidas e florestas com período de seca durante o inverno (Chen e Chen, 2013). A superseção foi caracterizada como de ampla distribuição e contínua na região centro-sul americana, em vegetações de florestas tropicais, porém disjunta para a região Sudeste do Brasil, e alcançando desta maneira a porção central da América do Sul.

A superseção Bryonioides (Figura 1-b) apresentou distribuição no sul da América do Norte, na América Central e nas regiões noroeste, leste e central da América do Sul. As características climáticas e fisionômicas para a América do Norte são de regiões desérticas quentes de baixa latitude e altitude, enquanto para a América Central e do Sul são florestas tropicais úmidas com período de seca durante o inverno ou durante o verão para a América Central (Chen e Chen, 2013). Os resultados demonstraram um padrão de distribuição amplo contínuo, que ocorre ao longo de quase todo continente americano, em florestas tropicais à oeste da Cordilheira dos Andes, transpassando a região andina no Peru e alcançando as florestas pluviais da Bolívia, Paraguai, Brasil e Argentina.

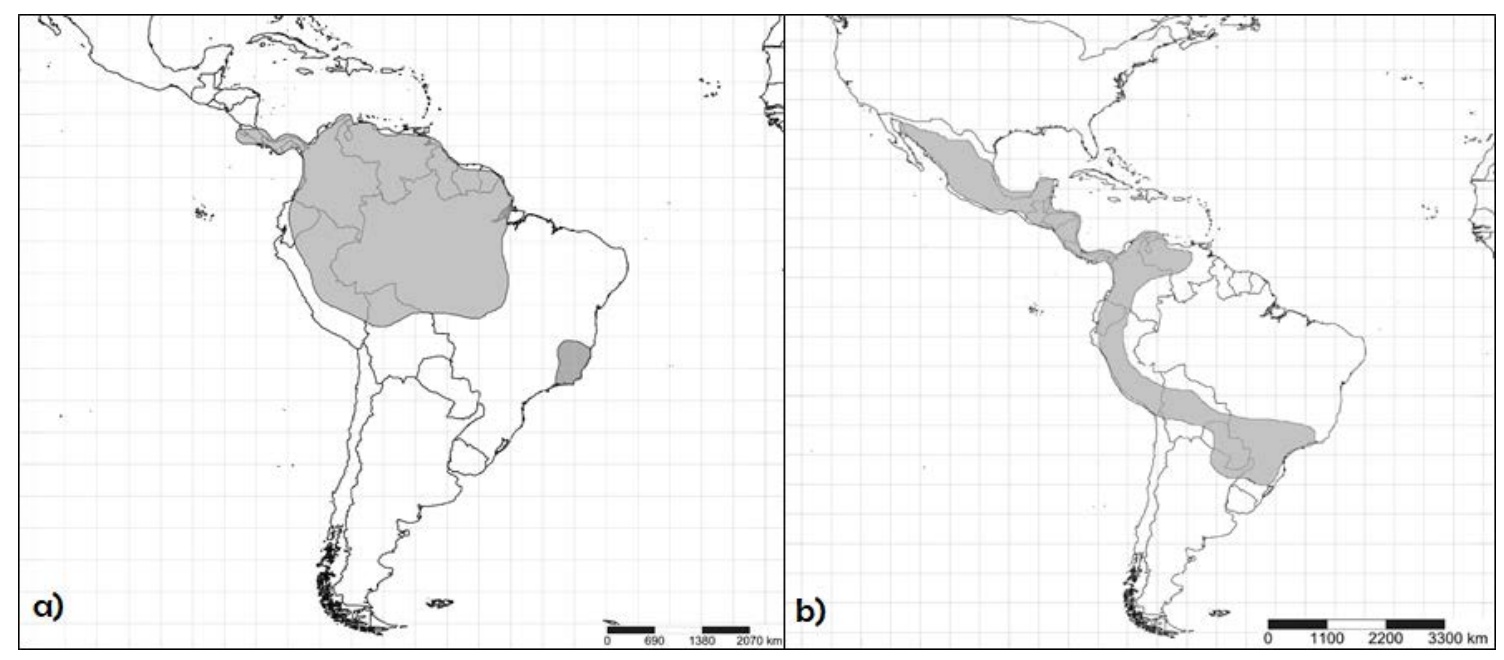

Figura 1. Distribuição geográfica das superseções Auriculata J.M. MacDougal \& Feuillet. com padrão disjunto (a) e da superseção Bryonioides (Harms) J.M. MacDougal \& Feuillet com padrão contínuo (b), ambas na América Central e América do Sul.

A distribuição da superseção Cieca (Figura 2-a) pode ser observada em toda a América Central e nas regiões noroeste e central da América do Sul. As características climáticas e fisionômicas podem ser definidas como florestas tropicais úmidas e florestas com período de seca durante o inverno ou durante o verão para a América Central, além de estepes quentes de baixa latitude e altitude em Galápagos, no Equador (Chen e Chen, 2013). A superseção possui ampla distribuição na área centro-sul americana e apesar da disjunção ocorrente pela separação de ilhas, seu padrão é contínuo devido a processos geológicos. 
A superseção Decaloba (Figura 2-b) apresenta a maior riqueza e abundância de espécies do subgênero e é dividida em duas seções Decaloba (DC.) MacDougal \& Feuillet sect. e Xerogona (Raf.) Killip. Esta superseção apresenta espécies com ampla distribuição geográfica, como P. biflora Lam., com distribuição nas Américas, P. lutea L., ocorrendo apenas na América do Norte (Estados Unidos e México) e P. sexflora Juss. na América do Norte e América Central. Estas espécies possuem entre 650 e 1.000 registros cada uma, apresentando grande representatividade nos sistemas de informação da biodiversidade.

Esta superseção ocorre por toda América Central e grande parte da América do Sul, além de uma relevante área da América do Norte. As características climáticas e fisionômicas podem ser definidas como regiões de clima temperado úmido com verões quentes no sudeste da América do Norte, florestas tropicais úmidas e florestas com período de seca durante o inverno na América do Sul ou durante o verão na América Central (Chen e Chen, 2013). A superseção possui ampla distribuição por todo continente americano, com um padrão contínuo e abrangendo espécies muito restritas, endêmicas, e com ampla distribuição.

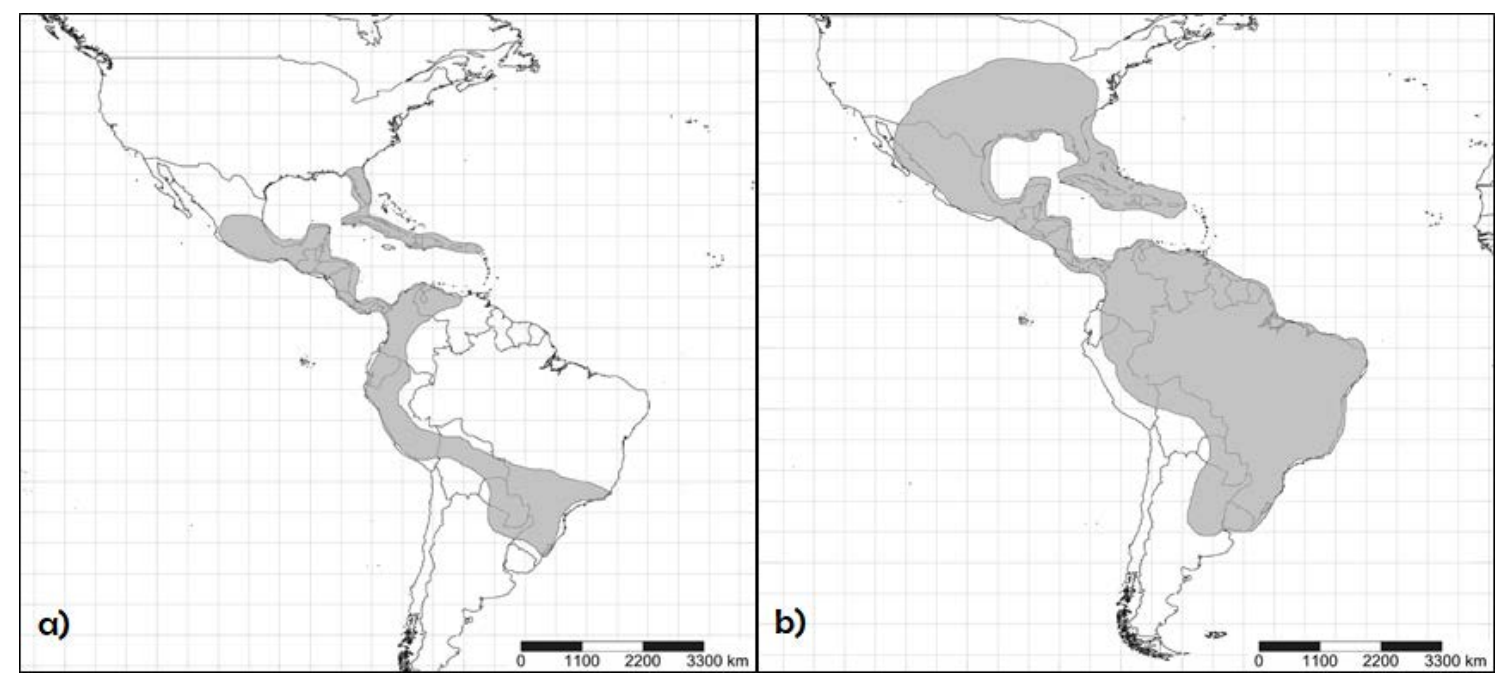

Figura 2. Distribuição geográfica das superseções Cieca (Medic.) J.M. MacDougal \& Feuillet, com padrão biogeográfico amplo contínuo, na América Central e América do Sul (a) e superseção Decaloba (DC.) J.M. MacDougal \& Feuillet com padrão amplo contínuo, em todo o continente americano (b).

A superseção Disemma (Figura 3-a) ocorre no continente Asiático e em parte da Oceania, vale ressaltar que a maior parte das espécies, estão alocadas na Ásia, enquanto a região da Austrália, conta com apenas três espécies. As características climáticas podem ser definidas como equatorial úmida nas ocorrências registradas na Ásia Meridional e no sudeste Asiático, clima temperado úmido com inverno seco e verão quente em parte da Ásia Oriental, onde existem registros de ocorrências da superseção e clima temperado úmido com verões quentes, nas ocorrências registradas na Austrália (Chen e Chen, 2013). Possui ampla distribuição e um padrão contínuo mesmo havendo disjunção na separação de ilhas, devido a processos geológicos passados. Importante salientar, que as três espécies que ocorrem apenas na Austrália podem ter sofrido especiação alopátrica, ou seja, processo evolutivo causado por barreira geográfica (e.g. oceano), levando a ocorrência de uma nova espécie, no caso da Austrália três espécies endêmicas. 
A distribuição da superseção Hahniopathantus (Figura 3-b) é encontrada apenas na América Central e na região norte da América do Sul. As características climáticas e fisionômicas são equatoriais de florestas tropicais úmidas e florestas com período de seca durante o inverno (Chen e Chen, 2013). É caracterizada com ampla distribuição e seu padrão é contínuo.

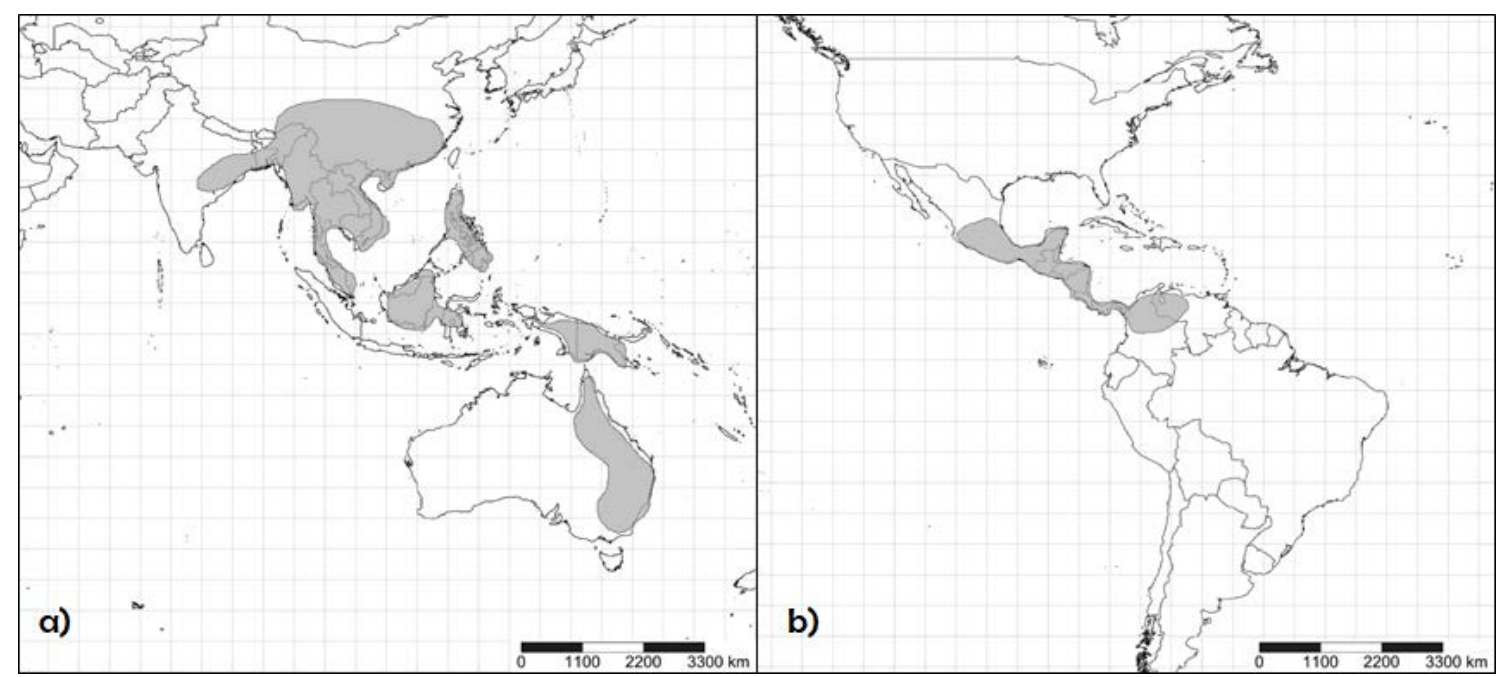

Figura 3. Distribuição geográfica das superseções Disemma (Labill.) J.M. MacDougal \& Feuillet, com padrão biogeográfico amplo contínuo, na Ásia e na Oceania e superseção (a) e Hahniopathantus (Harms) J.M. MacDougal \& Feuillet com padrão amplo contínuo na América Central (b).

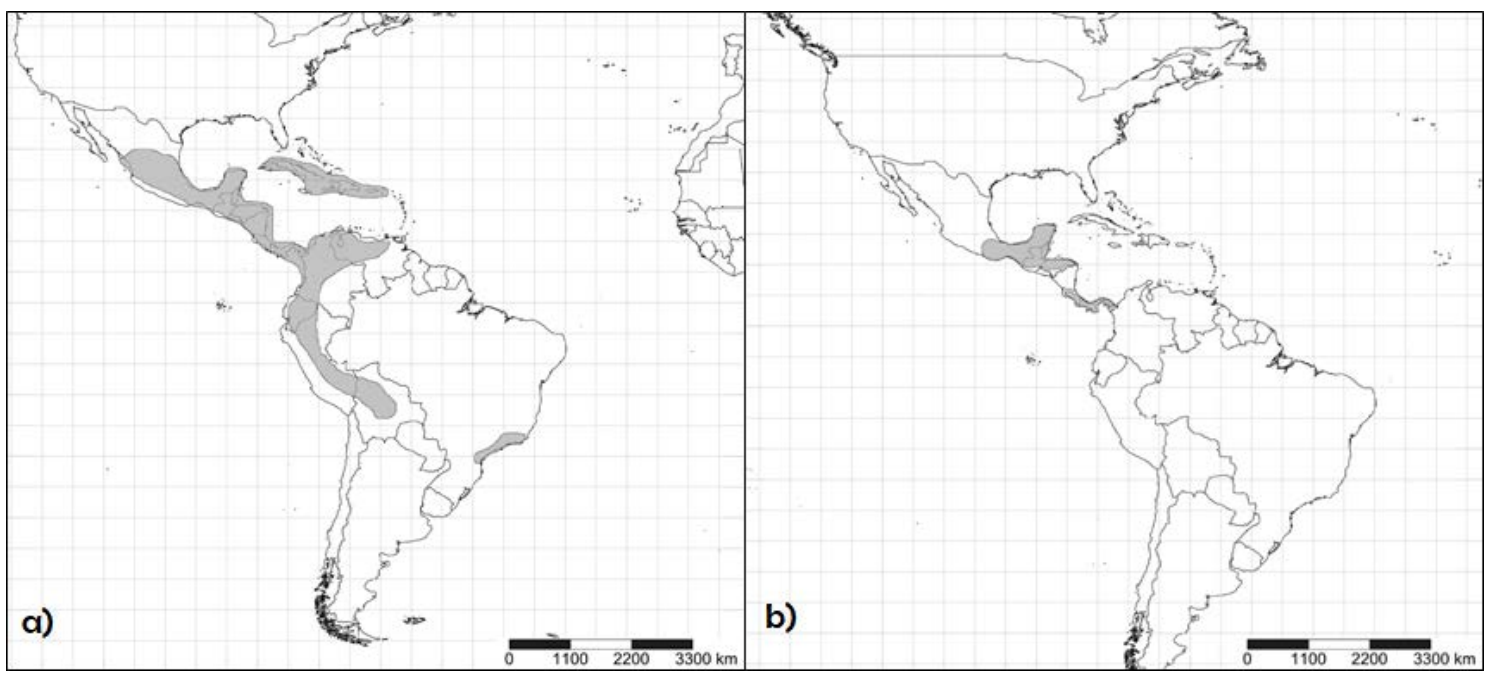

Figura 4. Distribuição geográfica das superseções Multiflora (Small) J.M. MacDougal \& Feuillet, com padrão biogeográfico disjunto, na América Central e América do Sul (a) e superseção e Pterosperma (L. Gilbert \& J.M. MacDougal) J.M. MacDougal \& Feuillet com padrão restrito contínuo na América Central (b). 
A superseção Multiflora (Figura 4-a) apresenta distribuição no sul da América do Norte, na América Central, e até as regiões nordeste, oeste e sudeste da América do Sul. As características climáticas e fisionômicas podem ser definidas como regiões desérticas quentes de baixa latitude e altitude para a localização na América do Norte, florestas tropicais úmidas e florestas com período de seca durante o inverno ou durante o verão para a América Central e do Sul (Chen e Chen, 2013). Possui ampla distribuição na Costa Andina, com um padrão biogeográfico disjunto, em Domínio Atlântico, nas regiões Sudeste e Sul do Brasil.

A superseção Pterosperma (Figura 4-b) é a superseção com distribuição geográfica mais restrita. Ocorre somente na América Central. As características climáticas e fisionômicas são equatoriais de florestas tropicais úmidas e florestas com período de seca durante o inverno (Chen e Chen, 2013). A superseção tem distribuição restrita abrangendo apenas cinco países da América Central, o padrão foi considerado contínuo, apesar da lacuna existente na Nicarágua, que pode ser atribuída a falta de coleta na área.

\section{Discussão}

Reiterando o estudo de Ulmer e MacDougal (2004), a América Central é considerada um centro de dispersão dos táxons do subgênero Decaloba, devido à grande concentração de espécies, muitas delas endêmicas. Porém, é importante salientar que todo o continente americano possui extrema relevância, por também apresentar uma grande diversidade de espécies e ampla distribuição dos espécimes, principalmente na América do Sul, com muitos táxons também endêmicos.

A centralização da distribuição do subgênero traz à tona a dispersão dos táxons na América Central, onde as espécies adentram a América do Sul, através dos Andes e do litoral pacífico, até chegar ao litoral atlântico. Sendo assim, é possível corroborar a hipótese da origem do gênero Passiflora na América Central (Krosnick, 2006; Muschner et al., 2012), devido à grande concentração de espécies nestas regiões, indicando o enveredamento por áreas de clima favorável, ou seja, regiões quentes de clima tropical e subtropical nos continentes americanos.

Além disso, dentro do total de espécies inclusas no subgênero, 17 são nativas do continente asiático e apenas três na Oceania, em território australiano, todas elas alocadas na superseção Disemma. Isso nos indica que as espécies são limitadas pela latitude, ou seja, o clima é um fator limitante de ocorrência, pois o maior número de espécies do gênero tem preferência por regiões com climas mais quentes. Logo, a América Central, que possui clima tropical, abriga a maior diversidade de espécies de Decaloba, favorecendo sua dispersão.

Segundo Muschner et al. (2012), um possível caminho para a dispersão da superseção Disemma pode ter sido através da Laurásia, durante o clima ótimo do Eoceno, que poderia explicar o motivo pelos quais muitos organismos agora têm distribuição disjunta nos trópicos da América do Sul, África e Sudeste Asiático, devido a sustentação da vegetação tropical (Richardson et al., 2004), como na família Passifloraceae s.s.

Sendo assim, a origem da dispersão do gênero Passiflora na América Latina e a migração para a América do Norte e Eurásia, através de uma ponte de terra oceânica, seria uma hipótese viável, um exemplo disso, seria o estreito de Bering, durante os períodos do Paleoceno/Eoceno, que apresentavam temperaturas mais quentes, que viabilizavam a distribuição (Muschner et al., 2012). Todavia, durante o período Oligoceno, as temperaturas globais, tiveram uma queda, sendo assim, o gênero foi desarraigado de regiões com climas mais frios e teve uma expansão em regiões com temperaturas mais altas (Krosnick, 2006).

Outra hipótese plausível para explicar a distribuição disjunta de espécies do único subgênero presente no velho mundo e Oceania é a transdispersão do Pacífico, como foi 
verificado por Sanmartín e Ronquist (2004) onde documentaram a dispersão de espécies vegetais da América do Sul até a Nova Zelândia. Essa dispersão pode ter sido provocada por diferentes fatores que ocorreram isolados ou em conjunto durante a história evolutiva, como (1) pelas correntes de ar com sentido leste-oeste (Swenson e Bremer, 1997), (2) dispersão realizada por grandes pássaros (Winkworth et al., 2002; Ulmer e MacDougal, 2004) e (3) presença de florestas de clima temperado ao longo do litoral da Antártida (Renner et al., 2000). Esses processos dispersivos já foram relatados para espécies com características semelhantes às do subgênero Decaloba (Clausing e Renner, 2001; Knapp et al., 2005). Com isso, a dispersão pela Antártida das espécies da América até o sudeste da Ásia e Austrália, podem explicar a monofilia encontrada por Krosnick e Freudenstein (2005) para as espécies Austral-Pacífico do subgênero Decaloba. A compreensão da origem, dispersão e evolução dessas espécies podem elucidar questões filogenéticas dentro do subgênero. As espécies pertencentes à superseção Disemma adaptaram-se e distribuíram-se pelas regiões tropicais e subtropicais da Ásia e Oceania. As localidades de ocorrência e registro no continente Asiático abrigam tanto o clima temperado em países como a China e Japão, quanto o clima mediterrâneo que cobre os países ocidentais como a Índia, propiciando uma melhor adaptação das espécies (Chen e Chen, 2013).

A grande diversidade e concentração de espécies na América Central, favoreceu a dispersão por boa parte do continente americano, devido sua adaptação ao clima tropical. Isto reforça as hipóteses de que as espécies de Passiflora tiveram sua origem na América Central, e enveredaram-se pelas regiões de clima tropical e subtropical da América Latina. O mesmo pode ser observado para a única superseção (Disemma) que não ocorre nas Américas.

Milward-de-Azevedo et al. (2012), num estudo de revisão do subgênero Decaloba apontou a ocorrência das espécies desde áreas de clima temperado e quente, no norte do México, adentrando formações vegetacionais em regiões tropicais de clima quente, nas Antilhas e América Central. Desta forma, as espécies alcançam, via cadeia andina, áreas subtropicais da América do Sul, ao norte do Uruguai, com clima temperado e frio. Foram destacados ainda, algumas espécies com características mais especialistas, com sensibilidade ao aumento ou diminuição da temperatura do planeta, assim como a dados de latitude/longitude e/ou altitude.

\section{Conclusão}

Os levantamentos bibliográficos e os mapeamentos realizados neste estudo corroboraram com a hipótese de que a origem do gênero Passiflora pertence à América Central migrando para a América do Sul, onde sua ocorrência é de porte mais intenso. As espécies encontradas nas regiões da Austrália e Ásia são restritas a estas áreas e não possuem ocorrência em outros continentes. As características de climas tropicais e de latitude são de extrema relevância para distribuição, visto que, o subgênero teve seu maior número em regiões mais quentes e com latitudes mais baixas. Apesar das superseções possuírem uma elevada distribuição geográfica, a maior parte das espécies são registradas em apenas um país ou domínio fitogeográfico específico. Estes mapas auxiliaram no reconhecimento dos padrões de distribuição geográfica, tendo sido evidenciadas as amplitudes geográficas, as faixas de ocorrência das superseções e seus núcleos predominantes.

\section{Agradecimentos}

Ao PROIC/UFRRJ e PIBIC/CNPq, pelas bolsas de iniciação científica concedida à primeira autora entre os anos 2014 e 2016. À Universidade Federal Rural do Rio de Janeiro pelo apoio institucional. 


\section{Conflito de interesses}

As autoras declaram não haver conflito de interesses.

\section{Referências}

Barreto, F. C. C. Potential distribution modelling as a tool to conservation: Algorithms selection and evaluation and application with Heliconius nattereri Felder, 1865 (Nymphalidae: Heliconiinae). Viçosa: Universidade Federal de Viçosa, 2008. (Tese de doutorado).

Bernacci, L. C.; Nunes, T. S.; Mezzonato, A. C.; Milward-de-Azevedo, M. A.; Imig, D. C.; Cervi, A. C. Passifloraceae. In: Flora do Brasil 2020. Rio de Janeiro: Jardim Botânico do Rio de Janeiro, 2020. Disponível em: <http://floradobrasil.jbrj.gov.br>. Acesso em: 12 jan. 2021.

Brown, J. H. Species diversity. In: Myers A. A.; Giller, P. S. (Eds.). Analytical biogeography. London: Chapman and Hall, 1988. p. 57-89.

Brown, J. H.; Lomolino, M. V. Biogeografia. Ribeirão Preto: FUNPEC, 2006.

Chen, D.; Chen, H. W. Using the Köppen classification to quantify climate variation and change: An example for 1901-2010. Environmental Development, v. 6, p. 69-79, 2013. https://doi.org/10.1016/j.envdev.2013.03.007

Clausing, G.; Renner, S. S. Molecular phylogenetics of Melastomataceae and Memecylaceae: Implications for character evolution. American Journal of Botany, v. 88, n. 3, p. 486-498, 2001. https://doi.org/10.2307/2657114

Collevatti, R. G.; Rabelo, S. G.; Vieira, R. F. Phylogeography and disjunct a distribution in Lychnophora ericoides (Asteraceae), an endangered Cerrado shrub species. Annals of Botany, v. 104, p. 655-664, 2009. https://doi.org/10.1093/aob/mcp157

Hawkins, B. A.; Porter, E. E.; Diniz-Filho, J. A. F. Productivity and history as predictors of the latitudinal diversity gradient of terrestrial birds. Ecology, v. 84, n. 6, p. 1608-1623, 2003. https://doi.org/10.1890/0012-9658(2003)084[1608:PAHAPO]2.0.CO;2

Knapp, M.; Stöckler, K.; Havell, D.; Delsuc, F.; Sebastiani, F. Relaxed molecular clock provides evidence for long-distance dispersal of Nothofagus (Southern Beech). PLoS Biology, v. 3, n. 1, e14, 2005. https://doi.org/10.1371/journal.pbio.0030014

Krosnick, S. E. Phylogenetic relationships and patterns of morphological evolution in the Old World species of Passiflora (subgenus Decaloba: Supersection Disemma and subgenus Tetrapathea). Columbus: The Ohio State University, 2006. (Ph.D. dissertation).

Krosnick, S. E.; Freudenstein, J. V. Monophyly and floral character homology of Old World Passiflora (Subgenus Decaloba: Supersection Disemma). Systematic Botany, v. 30, n. 1, p. 139-152, 2005. https://doi.org/10.1590/1678-4685-GMB-2016-0042

Krosnick, S. E.; Porter-Utley, K. E.; MacDougal, J. M.; Jorgensen, P. M.; McDade, L. A. New insights into the evolution of Passiflora subgenus Decaloba (Passifloraceae): Phylogenetic relationships and morphological synapomorphies. Systematic Botany, v. 38, p. 692-713, 2013. https://doi.org/10.1600/036364413X670359

MacArthur, R. H.; Wilson, E. O. The Theory of Island Biogeography. Princeton: Princeton University Press, 1967.

MacDougal, J. M.; Feuillet, C. Systematics. In: Ulmer, T.; MacDougal, J. M. (Eds.) Passiflora: Passionflowers of the World. 1. ed. Portland, Oregon: Timber Press, 2004. p. 27-31. 
Marchioretto, M. S.; Miotto, S. T. S.; Siqueira, J. C. Padrões de distribuição geográfica das espécies brasileiras de Pfaffia (Amaranthaceae). Rodriguésia, v. 60, n. 3, p. 667-681, 2009. https://doi.org/10.1590/2175-7860200960312

Milward-de-Azevedo, M. A. Análise da valoração dos impactos ambientais e da demanda de fitoterápicos oriundos do maracujá no Brasil. Revista FAE, v. 11, p. 19-32, 2008.

Milward-de-Azevedo, M. A.; Baumgratz, J. F. A.; Gonçalves-Esteves, V. A taxonomic revision of Passiflora subgenus Decaloba (Passifloraceae) in Brazil. Phytotaxa, v. 53, p. 1-68, 2012. https://doi.org/10.11646/phytotaxa.53.1.1

Muschner, V. C.; Zamberlan, P. M.; Bonatto, S. L.; Freitas, L. B. Phylogeny, biogeography and divergence times in Passiflora (Passifloraceae). Genetics and Molecular Biology, v. 35, n. 4, p. 1036-1043, 2012. https://doi.org/10.11646/phytotaxa.53.1.1

Renner, S. S.; Murray, D.; Foreman, D. Timing transantarctic disjunctions in the Atherospermataceae (Laurales): Evidence from coding and noncoding chloroplast sequences. Systematic Biology, v. 49, p.579-591, 2000. https://doi.org/10.1080/ 10635159950127402

Richardson, J. E.; Chatrou, L. W.; Mols, J. B.; Erkens, R. H. J.; Pirie, M. D. Historical biogeography of two cosmopolitan families of flowering plants: Annonaceae and Rhamnaceae. Philosophical Transactions of the Royal Society B, v. 359, p. 1495-1508, 2004. https://doi.org/10.1098/rstb.2004.1537

Sanmartín, I.; Ronquist, F. Southern hemisphere biogeography inferred by event-based models: Plant versus animal patterns. Systematic Biology, v. 53, p. 216-43, 2004. https://doi.org/10.1080/10635150490423430

Shorthouse, D. P. SimpleMappr, an online tool to produce publication-quality point maps. 2010. Disponível em: <https://www.simplemappr.net/>. Acesso em: 12 jan. 2021.

Swenson, U.; Bremer, K. Patterns of floral evolution of four Asteraceae genera (Senecioneae-Blennospermatinae) and the origin of white flowers in New Zealand. Systematic Biology, v. 46, p. 407-425, 1997. https://doi.org/10.2307/2413689

Thorne, R. Plant disjunctions: A personal reflection. International Journal of Plant Sciences, v. 165, p. 137-138, 2004. https://doi.org/10.1093/sysbio/46.3.407

Ulmer, T.; MacDougal, J. M. Passiflora: Passionflowers of the World. Portland Oregon: Timber Press, 2004.

Varassin, I. G.; Trigo, J. R.; Sazima, M. The role of nectar production, flower pigments and odour in the pollination of four species of Passiflora (Passifloraceae) in South-Eastern Brazil. Botanical Journal of the Linnean Society, v. 136, p. 139-152, 2001. https://doi.org/10.1111/j.1095-8339.2001.tb00563.x

Winkworth, R.; Wagstaff, S.; Glenny, D.; Lockhart, P. Plant dispersal N.E.W.S. from New

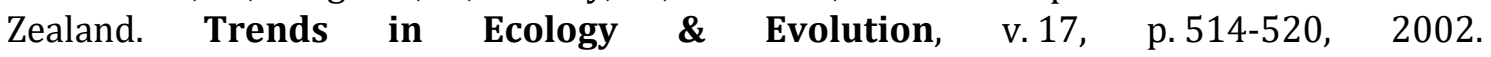
https://doi.org/10.1016/S0169-5347(02)02590-9

Informação da Licença: Este é um artigo Open Access distribuído sob os termos da Licença Creative Commons Attribution, que permite uso irrestrito, distribuição e reprodução em qualquer meio, desde que a obra original seja devidamente citada. 